\title{
Upaya Edukasi Pemuda Dalam Pencegahan Perkawinan Beda Agama
}

\author{
Mangiring Tua Togatorop ${ }^{1}$ Ardianto Lahagu ${ }^{2}$, Michael Cornelius Pua ${ }^{3}$, Rame Irma Ida \\ Ulina Wati Br Siregar ${ }^{5}$, Sukardin Zebua ${ }^{6}$ \\ 1, Prodi Teologi, STT Real Batam \\ 2, 3, 4, 5, 6 Prodi PAK, STT Real Batam \\ *togatoroptimo@gmail.com
}

\begin{abstract}
This research is a study on "Efforts to Prevent Interfaith Marriages for STT Real Batam Students. The main problems are: 1. What are the causes of the rise of interfaith marriages, 2. What efforts are being made to minimize the prevalence of interfaith marriages, 3. What is the solution to the rise of interfaith marriages? The goal is whether or not interfaith marriages are carried out according to religion according to the biblical perspective. The type of research used is qualitative research, with a sociological approach. The results of the study indicate that efforts to educate the basics and criteria in choosing a life partner according to the teachings of the Christian religion must be planted in Christian families as early as possible, so that wherever they are in the future or in whatever environment they are, they are still able to hold and have one principle. choosing the right life partner according to the Bible.
\end{abstract}

Keywords: Education, Youth, Prevention of Interfaith Marriages

Abstrak

Penelitian ini adalah studi tentang "Upaya Pencegahan Perkawinan Beda Agama bagi Mahasiswa STT Real Batam. Pokok permasalahannya: 1 . Apa penyebab maraknya perkawinan beda agama, 2. Upaya apa yang dilakukan unuk meminimalisir maraknya perkawinan beda agama, 3. Apa solusi maraknya pernikahan beda agama? Tujuannya adalah Boleh atau tidaknya Perkawinan beda agama dilangsungkan menurut agama menurut perspektif alkitab. Jenis penelitian yang digunakan adalah penelitian kualitatif, dengan pendekatan sosiologis. Hasil penelitian menunjukkan bahwa upaya didikan dasar-dasar dan kriteria-kriteria dalam memilih pasangan hidup menurut ajaran agama Kristian haruslah ditanam dalam diri keluarga Kristen sedini mungkin, sehingga dimanapun mereka berada kelak atau dilingkungan mana pun mereka, mereka tetap mampu untuk memegang dan mempunyai satu prinsip pemilihan pasangan hidup yang benar menurut Alkitab.

Kata kunci: Edukasi, Pemuda, Pencegahan Perkawinan Beda Agama

\section{PENDAHULUAN}

Adalah menjadi peranan bagi gereja dan keluarga untuk menanamkan dasar-dasar perkawinan menurut Alkitab Perjanjian Lama mahupun Perjanjian Baru kepada anak-anak. Tujuan perkawinan adalah untuk melahirkan keturunan-keturunan ilahi yang serupa dan segambar dengan Allah .Tuhan menciptakan Adam dan Hawa pada mulanya adalah serupa dan segambar denganNYA. Keturunan ilahi bermaksud keturunan yang menyembah dan taat kepada Allah yang telah menciptakan segala sesuatu yang dapat kita kenal dalam nama Tuhan Yesus Kristus.

Perkawinan beda agama bukanlah sebuah perkawinan yang dapat dibanggakan dalam agama Kristen kerana perkawinan seperti ini telah membawa muda-mudi kristen menjauhkan dirinya dari persekutuannya dengan Allah. Dalam kitab Kejadian menjelaskan bahawa perkawinan yang diberkati adalah perkawinan yang ditentukan oleh Allah sendiri. Dimana pasangan itu menjadi pasangan yang seimbang seperti Adam dan Hawa (Kejadian 2:22-23). Allah sendiri yang telah menempatkan Hawa disisi Adam menjadi isterinya yang sah dan sebelum mereka melahirkan keturunan, Allah terlebih dahulu memberkati mereka. Hawa ketika dipersatukan dengan Adam mengenal Tuhan yang juga dikenal oleh Adam. Disini dapat lihat bahawa keluarga Adam dan Hawa mengenal Tuhan yang sama. Melalui kitab Kejadian, perkawinan yang diberkati dan diinginkan Tuhan adalah perkawinan yang mana Allah turut hadir dan berkerja buat keluarga baru yang dibangun. 
Sangat penting buat setiap anak-anak muda Kristen untuk diberi pengajaran-pengajaran yang benar tentang memilih pasangan hidupnya. beriman kepada Tuhan Yesus merupakan sesuatu yang mutlak dimiliki kedua pasangan dalam membangun sebuah pernikahan supaya keluarga itu berkenan dihadapan Tuhan. Penatalayanan merupakan bagian dari pelayanan gereja yang sangat penting, gereja harus memberikan pemahaman menurut agama kristen tentang memilih pasangan karena itu merupakan bagian dari perintah Tuhan yang harus dilaksanakan oleh gereja. Pendidikan ini tidak boleh diabaikan oleh gereja. ${ }^{1}$ Dalam kitab Keluaran 34 : 16, dijelaskan apabila bangsa israel mengambil pasangan perempuan Filistin maka anak-anak lelaki israel akan sujud menyembah dewa orang filistin. Itulah sebabnya Tuhan melarang bangsa Israel mengambil wanita filistin menjadi pasangan hidup mereka.

Orang tua juga harus memainkan peranan penting dalam penanaman nilai-nilai kekristenan dalam diri setiap anak baik laki- laki maupun perempuan. Orang tua dipanggil untuk menyatakan kasih Allah kepada anak-anak melalui teladan, pengajaran, tuntunan dalam pelbagai bentuk ibadah keluarga. Kedewasaan rohani ini akan menolong anak dan memampukan dia untuk mengaktualisasikan imannya dalam kehidupan sehari-hari lebih-lebih lagi dalam hal memilih pasangan hidup.

Pasangan yang tidak seimbang ialah orang yang tidak percaya kepada Kristus dan meletakkan kepercayaannya kepada ilah-ilah lain. Rasul Paulus menekankan agar jangan merupakan pasangan yang tidak sama dari segi kepercayaan, iman dan pengharapan. Yang dimaksudkan disini ialah orangorang yang bukan menjadi pengikut Kristus dimana mereka mengadakan hubungan-hubungan dengan ilah-ilah lain dari segi ritual dan penyembahan berhala dan terlibat langsung dengan kuasa-kuasa kegelapan. Ditekankan agar semua orang yang percaya termasuk orang Kristen zaman ini juga ditekankan agar tidak mengikat diri didalam perkawinan dengan orang yang tidak seimbang atau dikenali sebagai berbeda agama dan kepercayaan. Apabila perbedaan agama ini bersatu didalam satu keluarga, secara perlahan-lahan orang percaya yang berkahwin dengan orang tidak percaya ini dengan perlahan-lahan akan mengabaikan ajaran-ajaran Firman sehingga menjadi durhaka terhadap Tuhan. Allah melarang perkawinan semacam ini kerana akan dapat menarik orang yang percaya untuk menduakan Tuhan dengan menyembah ilah pasangan. Ia bertolak belakang dengan tujuan Allah dalam perkawinan manusia iaitu melahirkan keturunan Ilahi. Bagaimana mungkin dapat melahirkan keturunan Ilahi sekiranya orang tua tidak mempercayai Allah.

\section{METODE}

Jenis penelitian yang digunakan adalah penelitian kualitatif, dengan pendekatan sosiologis. Metode pengumpulan data; observasi, interview, dan dokumentasi, dengan teknik analisis data; reduksi data, display data, dan penarikan kesimpulan. Metode Analisis Deskriptif adalah usaha untuk mengumpulkan dan menyusun suatu data, kemudian dilakukan analisis terhadap data tersebut." "Selain itu, semua yang dikumpulkan kemungkinan menjadi kunci terhadap apa yang sudah diteliti." Dengan demikian, laporan penelitian akan berisi kutipan-kutipan data untuk memberi gambaran penyajian laporan tersebut.

Menurut Weber, analisisa isi adalah ilmu yang memanfaatkan seperangkat prosedur untuk menarik kesimpulan yang sah dari sebuah pengumpulan. Menurut Hostli bahwa analisis isi adalah teknik apapun yang digunakan untuk menarik kesimpulan melalui usaha untuk menemukan karekteristik

\footnotetext{
${ }^{1}$ Agung Gunawan, "Pendidikan Kristen Bagi Kaum Muda: Menjawab Pergumulan Kaum Muda," Jurnal Teologi Aletheia 7, no. 12 (2015). 3

${ }^{2}$ Winarno Surachman, Pengantar Penelitian Ilmiah: Dasar, Metode, Teknik (Bandung: Tarsita, 1990).

${ }^{3}$ Lexy J Moleong, Metodologi Penelitian Kualitatif (Bandung: PT Remaja Rosdakarya, 2002).
} 
pesan, dan dilakukan secara objektif. ${ }^{4}$ Kajian ini disamping dengan cara analisis isi dapat juga dibandingkan antara satu buku dengan buku yang lain dalam bidang yang sama,baik berdasarkan perbedaan waktu penulisannya maupun mengenai kemampuan buku-buku tersebut dalam mencapai sasaran sebagai bahan yang disajikan kepada masyarakat atau sekelompok masyarakat tertentu. Kegiatan edukasi diadakan satu hari pada tanggal 14 Februari 2018 di kelompok Dewasa Muda GBI My Home Tanjungpinang

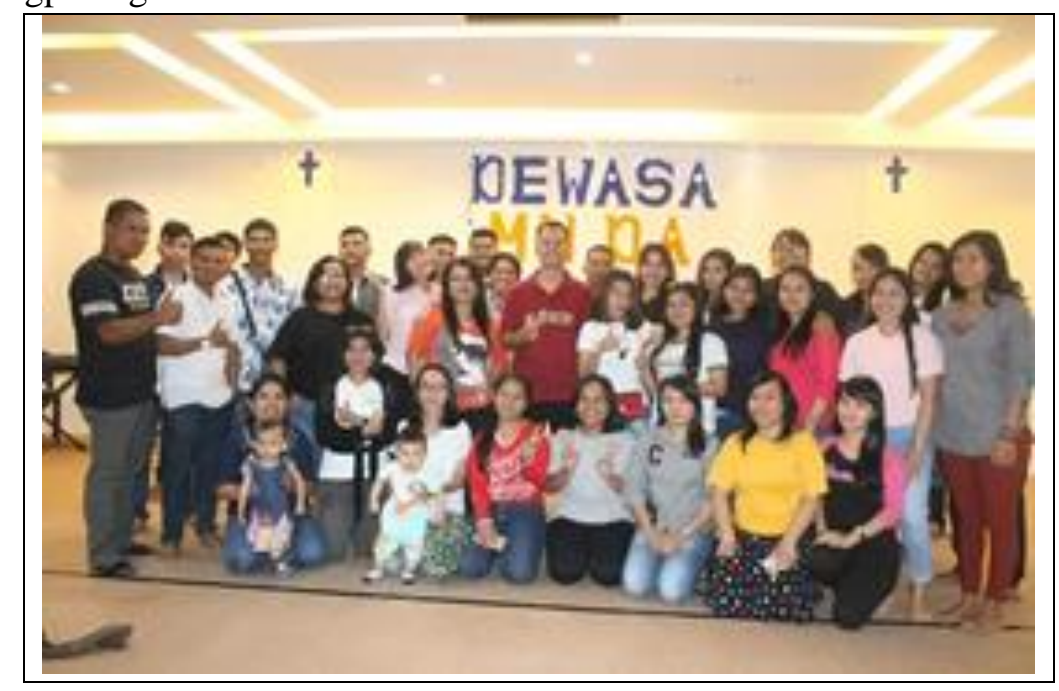

Gambar 1. Dosen Berfoto Bersama Pemuda

\section{HASIL DAN PEMBAHASAN}

\section{Konsep Perkawinan Agama Kristian}

Agama Kristian adalah sebuah kepercayaan yang berdasarkan pada ajaran, hidup, penderitaan, penyaliban, kematian, kebangkitan, kenaikan ke Sorga dan kedatangan Yesus Kristus ke dunia untuk kedua kali. Mereka beribadah di gereja dan menggunakan Alkitab sebagai Kitab Suci yang mengandungi dua bahagian utama yaitu Perjanjian Lama dan Perjanjian Baru. Agama ini meyakini sepenuhnya bahawa Yesus Kristus ialah Mesias, Tuhan dan Juruselamat bagi seluruh umat manusia dan lahir kedunia dengan satu misi iaitu untuk menebus manusia dari dosa kerana manusia tidak mampu untuk datang kepada Allah dengan kekuatan dan perbuatan baik melainkan hanya didalam karya penebusan Yesus iaitu Tuhan sendiri yang telah menjadi manusia dapat membawa umat manusia kepada kehidupan kekal.

\section{Pencegahan Perkawinan Beda Agama Menurut Agama Kristian}

Perkawinan beda agama menurut agama Kristian sesuatu yang dilarang. Ada beberapa alasan mengapa perkawinan beda agama dilarang dalam agama Kristian. Meskipun agama Kristen memegang hukum kasih kepada sesama manusia, tetapi ia bukanlah berarti bisa dan bebas untuk mengikat diri dalam perkawinan beda agama. Alasan-alasan itu adalah seperti berikut: ${ }^{5}$

Pertama, Tidak Dapat Berkerjasama Dengan Pasangan Untuk Menyenangkan Hati Tuhan. Didalam perkawinan memerlukan kerjasama antara dua individu untuk menyelenggarkan hidup dalam rangka untuk menyenangkan hati Tuhan. Jika pasangan adalah merupakan beda agama pasti hal ini tidak dapat dicapai.

Kedua, Menjadi batu sandungan bagi banyak orang. Apabila seseorang berkeputusan untuk berkahwin dengan pasangan beda agama, ramai orang akan tersakiti dengan tindakan tersebut kerana membuat suatu keputusan yang tidak bijak bahkan didapati bahawa dia bukanlah seorang Kristen yang taat kepada ajaran Tuhan.

\footnotetext{
${ }^{4}$ Ibid. 163

${ }^{5}$ Bagas Karyadi, “Alasan Orang Kristen,” Bagas.Org, last modified 2015, http://www.bagas.org/2015/07/3-alasan-orang-kristian-tidak-boleh.html.
} 
Ketiga, Hati Tuhan akan tersakiti. Orang-orang Kristian merupakan orang yang telah diangkat dari gelap kepada terang Tuhan. Oleh itu, Tuhan tidak mengiinginkan anak-anaknya kembali dan menjadi satu dengan anak-anak gelap iaitu orang-orang yang tidak percaya kepada ketuhanan Yesus kerana itu akan menyakiti hati Tuhan.

Surat Rasul Paulus 2 Korintus 6:14-15 menyatakan agar tidak menjadi pasangan yang tidak seimbang. Ayat ini merupakan larangan terhadap seorang Kristian untuk menikah dengan non-Kristian karena sudah jelas pasangan non-Kristian ini tidak seimbang/seiman dalam hal percaya kepada Tuhan Yesus Kristus. Perkawinan Kristian melambangkan hubungan Kristus dengan jemaat adalah ekslusive dan kudus. Dalam Efesus 5: 22-33 dijelaskan bahawa sama seperti suami harus mengasihi isteri sama seperti Kristus dan isteri harus tunduk kepada suami seperti tunduk kepada Kristus.

Menurut David Atkinson sebagaimana dikutip oleh John Scott, menegaskan bahawa Alkitab menganggap perkhawinan itu sebagai suatu perjanjian yang suci dimana melibatkan 'perjanjian Allah' seperti yang terdapat dalam Amsal 2:17, yaitu 'yang meninggalkan teman hidup masa mudanya, dan melupakan perjanjian Allahnya'. Disini jelas dikatakan bahawa Allah sendiri terlibat dalam perjanjian ini. Allah juga yang merencanakannya sehingga terbentuknya institusi keluarga serta menjadi saksi bagi lafaz perjanjian yang dilakukan oleh kedua mempelai ${ }^{6}$

\section{Faktor-Faktor Yang Menyebabkan Terjadinya Perkawinan Beda Agama}

Beberapa faktor dan dorongan sehingga dapat mempengaruhi terjadinya perkawinan beda agama. Berikut merupakan beberapa faktor yang mempengaruhi perkawinan beda agama: ${ }^{7}$

\section{Pergaulan Hidup Sehari-Hari Dalam Bermasyarakat}

Dalam kehidupan pergaulan sehari-hari, masyarakat tidak pernah dibatasi untuk hidup bersosial antara satu suku, agama dengan yang lain. Kehidupan masyarakat majemuk mendorong masyarakat untuk hidup rukun dan saling, konsep itu juga timbul dalan diri setiap golongan termasuk muda-mudinya. Hal ini dapat memberi pengaruh yang sangat kuat bagi kaum muda karena dengan keakraban persahabatan tanpa memandang agama yang dianuti menimbulkan perasaan cinta yang tidak dapat dihindari.

\section{Kurangnya Pendidikan Agama}

Seperti yang sudah ditekankan bahwa pendidikan agama sangat penting bagi muda-mudi, selain tanggung jawab gereja, orang tua juga harus bertanggungjawab dalam memberikan Pendidikan agama terhadap anak-anaknya sehingga mereka kuat dalam imannya. Fakta yang terjadi terkadang orang tua jarang bahkan tidak pernah sama sekali mengajarkan agama kepada anaknya. Hal ini menyebabkan anak-anak semasa dalam pertumbuhannya tidak mempermasalahkan jika dirinya nanti pada waktu mau menikah memiliki pasangan yang berbeda agama bahkan meninggalkan imannya untuk mengikuti kepercayaan pasangannya. Orang tua bertanggung jawab mengajarkan Firman Tuhan kepada anak-anaknya supaya mereka tetap berjalan dalam ketetapan Tuhan (Ulangan $6: 7-15$ ).

\section{Latar Belakang Orang Tua}

Latar belakang orang tua juga memainkan peranan penting terjadinya perkawinan beda agama. Contohnya, anak muda beragama Kristen mengikuti agama ibunya yang beragama Kristen tetapi ayahnya beragama Buddha. Perbedaan agama orang tua juga merupakan patokan bagi anak untuk berkahwin dengan pasangan beda keyakinan. Dan keharmonisan yang dialami oleh anak sepanjang hidup dalam keluarga yang berbeda keyakinan menambahkan meyakinkannya dan dapat dijadikan contoh bagi dirinya dalam membangun keluarga yang terdiri dari beda agama.

\section{Kebebasan Memilih Pasangan}

\footnotetext{
${ }^{6}$ John Stott, Isu-Isu Global: Menantang Kepemimpinan Kristen (Jakarta: Yayasan Komunikasi Bina Kasih/OMF, 1993). 393

7 Jane Marlen Makalew, “Akibat Hukum Dari Perkawinan Beda Agama Di Indonesia,” Lex Privatum 1, no. 2 (2013). 138
} 
Dalam zaman yang serba moden ini memberi peluang kepada anak muda untuk bebas mengadakan hubungan cinta dengan sesiapa sahaja yang mereka sukai. Berbeda dengan zaman dahulu kala, pemilihan pasangan hidup ditentukan oleh orang tua. Orang tua lah yang bertanggungjawab dalam mencarikan jodoh bagi anaknya perempuan mahupun laki-laki. Namun, zaman ini tidak lagi demikian. Dengan adanya kebebasan memilih pasangan hidup, tidak dapat dimungkiri jika banyak yang memilih untuk berkahwin dengan pasangan beda agama didasari oleh perasaan cinta. Jika cinta telah mendasari hubungan seorang laki-laki dan perempuan, maka pertimbangan secara matang termasuk soal agama yang tidak membenarkan perkawinan beda agama dilakukan kurang berkesan dan tidak kurang yang menutup mata dalam soal ini.

\section{Akibat Perkawinan Beda Agama}

Perkawinan beda agama selalu diperingatkan baik dari orang tua, gereja maupun orang-orang kristian secara umumnya agar tidak dilakukan. Peringatan ini diberikan bukan hanya kepada orang yang ingin menikah dengan pasangan beda agama tetapi juga kepada setiap orang percaya yang akan menikah. kerana perkawinan beda agama akan membawa dampak yang besar dan membahayakan imannya terhadap Tuhan Yesus Kristus. Bahaya kepada imannya diidentikkan dengan bahaya bahawa orang yang berkahwin beda agama akan mengambil jarak dari lembaga gerejani. Pengambilan jarak dari gereja dan kegiatan-kegiatan yang ada didalamnya merupakan petunjuk-petunjuk bahawa seseorang sudah mulai menjauhi hidup dari persekutuan dengan Tuhan. ${ }^{8}$ Apabila hal ini terjadi maka lambat laun orang tersebut akan melupakan dan meninggalkan ajaran agamanya dan tidak mustahil akan mengikuti ajaran agama pasangannya sekiranya pasangan itu lebih dominan dan kuat dengan pegangan agamanya. Akibatnya akan menjadi pendurhaka kepada Tuhan.

\section{Konsep Memilih Pasangan Hidup}

Dalam kamus KBBI Online "pasangan" didefinisikan sebagai seorang perempuan bagi lakilaki; yang merupakan pelengkap bagi yang lain; yang menjadi padanannya (jodohnya, teman bermainnya, dsb); partner. ${ }^{9}$ Dalam kamus Dwibahasa Oxford Fajar Bahasa Inggeris -Spouse berarti suami atau isteri. Jadi dapatlah diertikan disini bahawa pasangan hidup merupakan seorang lelaki bagi wanita dan seorang wanita bagi lelaki dimana akan menjadi pelengkap hidupnya, menjadi teman dalam menjalani hidup atau lebih jelas dikatakan sebagai suami atau isteri.

Prinsip-prinsip memilih pasangan hidup menurut Samuel T. Gunawan ialah seperti berikut:

Pertama, pasangan yang dipilih itu haruslah di antara yang seiman yaitu menyembah dan percaya kepada Tuhan Yesus Kristus, kedua ialah pasangan yang bertekad untuk mengikat perjanjian kahwin dihadapan Tuhan dan benar-benar faham bahawa Tuhan menjadi saksi atas perkawinan mereka kelak, ketiga bertekad untuk memelihara kekudusan dan kesetiaan. Sebagaimana Tuhan yang merencanakan dan menjadi saksi perkawinan itu kudus dan setia maka pasangan dituntut juga bersikap kudus dan setia dalam hal perkawinan. Keempat, bertekad untuk saling mengasihi didalam Tuhan iaitu menjalani hari-hari kedepan dengan cinta dan kasih sayang baik suami kepada isteri dan sebaliknya. Kelima bertekad untuk mendidik anak-anak sesuai kebenaran Firman Tuhan agar keturunankerturunan tetap menyembah Allah yang benar dan menikmati berkat-berkat yang telah disediakan bagi umat-Nya dan terakhir mengatasi semua persoalan berdasarkan kebenaran Firman Tuhan dimana memusatkan keputusan-keputusan keluarga baik suka ataupun duka dalam kendalian Allah. ${ }^{10}$

\section{SIMPULAN}

Agar perkawinan beda agama dapat dicegah haruslah berlandaskan kepada kebenaran Firman Tuhan seperti yang terdapat dalam 2 Korintus 6: 14-15. Intinya ialah pertama, harus memilih pasangan yang seimbang. Pasangan seimbang disini adalah pasangan yang sama dari segi kepercayaan, iman dan pengharapan kepada Kristus yang berarti sama-sama memiliki kepercayaan

\footnotetext{
${ }^{8}$ Weinata Sairin and J M Pattiasina, Pelaksanaan Undang-Undang Perkawinan Dalam Perspektif Kristen (Jakarta: BPK Gunung Mulia, 1996). 119

9 "Kamus Besar Bahasa Indonesia," KBBI WEB, https://kbbi.web.id/.

${ }^{10}$ Samuel T Gunawan, "Situs Artikel Kristen Indonesia,” Artikel.Sabda.Org.
} 
kepada Yesus Kristus atau beragama Kristen. Kedua, harus memilih pasangan yang hidup dalam kebenaran Firman Tuhan. Pasangan yang dipilih bukan saja beragama Kristian tetapi juga hidup dengan melakukan kehendak Allah. Perilaku yang benar dihadapan Tuhan dan memiliki hubungan persekutuan yang benar dengan kepada Kristus serta percaya bahwa Kristus ialah Tuhan dan Juruselamat peribadinya.

Dengan mengetahui konsep memilih pasangan hidup seperti diatas, dapat membantu pihak gereja, keluarga maupun orang percaya secara umum dan khususnya kaum muda- mudi Kristen dapat mencegah terjadinya perkawinan beda agama.

\section{DAFTAR PUSTAKA}

Gunawan, Agung. "Pendidikan Kristen Bagi Kaum Muda: Menjawab Pergumulan Kaum Muda." Jurnal Teologi Aletheia 7, no. 12 (2015).

Gunawan, Samuel T. "Situs Artikel Kristen Indonesia." Artikel.Sabda.Org.

Karyadi, Bagas. "Alasan Orang Kristen.” Bagas.Org. Last modified 2015. http://www.bagas.org/2015/07/3-alasan-orang-kristian-tidak-boleh.html.

Makalew, Jane Marlen. “Akibat Hukum Dari Perkawinan Beda Agama Di Indonesia.” Lex Privatum 1 , no. 2 (2013).

Moleong, Lexy J. Metodologi Penelitian Kualitatif. Bandung: PT Remaja Rosdakarya, 2002.

Sairin, Weinata, and J M Pattiasina. Pelaksanaan Undang-Undang Perkawinan Dalam Perspektif Kristen. Jakarta: BPK Gunung Mulia, 1996.

Stott, John. Isu-Isu Global: Menantang Kepemimpinan Kristen. Jakarta: Yayasan Komunikasi Bina Kasih/OMF, 1993.

Surachman, Winarno. Pengantar Penelitian Ilmiah: Dasar, Metode, Teknik. Bandung: Tarsita, 1990.

"Kamus Besar Bahasa Indonesia." KBBI WEB. https://kbbi.web.id/. 